\title{
Mannose-binding lectin-associated serine protease 2 (MASP-2) contributes to poor disease outcome in humans and mice with pneumococcal meningitis
}

E. Soemirien Kasanmoentalib ${ }^{1}$, Mercedes Valls Seron ${ }^{1}$, Bart Ferwerda ${ }^{1}$, Michael W. Tanck ${ }^{2}$, Aeilko H. Zwinderman², Frank Baas ${ }^{3}$, Arie van der Ende ${ }^{4,5}$, Matthijs C. Brouwer ${ }^{1}$ and Diederik van de Beek ${ }^{1,6^{*}}$

\begin{abstract}
Background: Pneumococcal meningitis is the most common and severe form of bacterial meningitis. Fatality rates are substantial, and long-term sequelae develop in about half of survivors. Disease outcome has been related to the severity of the pro-inflammatory response in the subarachnoid space. The complement system, which mediates key inflammatory processes, has been implicated as a modulator of pneumococcal meningitis disease severity in animal studies.

Methods: We investigated mannose-binding lectin-associated serine protease (MASP-2) levels in cerebrospinal fluid (CSF) samples derived from the diagnostic lumbar puncture, which was available for 307 of 792 pneumococcal meningitis episodes included in our prospective nationwide cohort study (39\%), and the association between these levels and clinical outcome. Subsequently, we studied the role of MASP-2 in our experimental pneumococcal meningitis mouse model using $\mathrm{Masp}^{-/-}$mice and evaluated the potential of adjuvant treatment with MASP-2-specific monoclonal antibodies in wild-type (WT) mice.
\end{abstract}

Results: MASP-2 levels in cerebrospinal fluid of patients with bacterial meningitis were correlated with poor functional outcome. Consistent with these human data, Masp2-deficient mice with pneumococcal meningitis had lower cytokine levels and increased survival compared to WT mice. Adjuvant treatment with MASP-2-specific monoclonal antibodies led to reduced complement activation and decreased disease severity.

Conclusions: MASP-2 contributes to poor disease outcome in human and mice with pneumococcal meningitis. MASP-2specific monoclonal antibodies can be used to attenuate the inflammatory response in pneumococcal meningitis.

\section{Background}

Acute community-acquired bacterial meningitis is a lifethreatening disease associated with substantial morbidity and mortality and ranks among the top ten infectious causes of death [1]. Streptococcus pneumoniae is the most common cause of bacterial meningitis in adults accounting for $50-70 \%$ of cases in developed countries [2, 3]. Pneumococcal meningitis is associated with a mortality

\footnotetext{
* Correspondence: d.vandebeek@amc.nl

1 Department of Neurology, Academic Medical Center, Amsterdam Neuroscience, Amsterdam, The Netherlands

${ }^{6}$ Department of Neurology, Academic Medical Center, University of Amsterdam, Amsterdam Neuroscience, PO Box 226601100 DD Amsterdam, The Netherlands

Full list of author information is available at the end of the article
}

ranging from 19 to $37 \%$, and neurological sequelae such as hearing loss, focal deficits, and motor and cognitive impairments significantly affect the quality of life of survivors [2, 4-6]. Predisposing factors for pneumococcal meningitis include pneumonia, otitis, sinusitis, cerebrospinal fluid (CSF) leaks, splenectomy or asplenic states, and primary or acquired immune deficiencies [3, 5]. Genetic studies of extreme phenotypes have revealed that patients with single-gene inborn errors in MyD88, IRAK4, and NEMO affecting the activation of the canonical Toll-like receptor (TLR) and interleukin (IL)-1R signaling pathways or in complement components are susceptible for invasive pneumococcal disease [7-10].

Experimental studies in pneumococcal meningitis showed that the host inflammatory response also 
contributes to an adverse outcome [11]. The initial host inflammatory response is activated by recognition of pathogen-associated molecular patterns by the innate immune system, e.g., by Toll-like receptors and inflammasomes [11]. Subsequently, the complement system is activated, leading to massive release of anaphylotoxins and chemotaxis and activation of neutrophils [11]. Genetic variants in complement system, TLR and IL-1R signaling pathways, and the M-TOR pathway have been identified to be associated with outcome in pneumococcal meningitis [7, 9, 12-15]. Inhibition of the final common pathway in the complement cascade has been identified as target for adjunctive treatment for experimental pneumococcal meningitis. Complement component 5 (C5) inhibition was shown to reduce inflammation of the central nervous system and improve outcome $[13,16]$. C5 inhibition shuts down the terminal complement effector pathway but does not prevent the release of anaphylatoxin C3a and other upstream complement activation events. Therefore, inhibition of the upstream activation pathways of the complement system may result in a more complete reduction of complement-mediated inflammation.

The classical pathway was initially proposed as the predominant pathway responsible for complement activation during pneumococcal infection [17]. C1q-deficient mice in which the classical pathway is disrupted and factor Bdeficient mice with a defective alternative pathway were both more susceptible to intranasal and intraperitoneal pneumococcal infection compared to wild-type mice. Mice deficient in complement factor 3, affecting all pathways of complement activation, had increased susceptibility to invasive pneumococcal infection, as compared to C1q, factor B, and $\mathrm{C} 1 \mathrm{q} /$ FactorB knockouts, suggesting an additional and important role of the lectin pathway in pneumococcal infection [17]. This was confirmed by a study in Masp2-deficient mice that showed increased susceptibility to intranasal pneumococcal infection due to decreased opsonization of S. pneumoniae [18]. Masp2-deficient mice had similar survival times and mortality rates compared to those previously reported in C1q-deficient mice [18].

Thus, an intact complement system protects against contraction of pneumococcal infection; however, in view of the detrimental role of inflammation in disease progression, inhibition of mannose-binding lectin-associated serine protease (MASP-2) presents to be an interesting target for complement blockade aiming to decrease inflammation in pneumococcal meningitis. We studied multiple aspects of the role of MASP-2 in pneumococcal meningitis. First, we measured MASP-2 in CSF of pneumococcal meningitis patients. Subsequently, we analyzed the role of MASP-2 during experimental meningitis in our validated pneumococcal meningitis mouse model using Masp2 knockout mice. Finally, we studied whether treatment with MASP-2 antibodies improved outcome in a randomized controlled investigator-blinded mouse experiment.

\section{Methods \\ Dutch bacterial meningitis cohort}

In a nationwide prospective cohort study, we included adults with community-acquired bacterial meningitis with positive CSF cultures who were identified by the Netherlands Reference Laboratory for Bacterial Meningitis (NRLBM). Methods have been described in detail previously [19]. The NRLBM provided the names of the hospitals where patients with bacterial meningitis had been admitted 2 to 6 days previously. The treating physician was contacted, and informed consent was obtained from all participating patients or their legally authorized representatives. Outcome was graded at discharge according to the Glasgow Outcome Scale (GOS), a well-validated instrument [20]. A score of 1 indicates death; a score of 2 indicates a vegetative state; a score of 3 indicates severe disability; a score of 4 indicates moderate disability; and a score of 5 indicates mild or no disability. A favorable outcome was defined as a score of 5 and unfavorable outcome as a score of 1 to 4 . The study was approved by the medical ethical committee of the Academic Medical Centre, Amsterdam, the Netherlands.

\section{CSF measurements}

To evaluate whether MASP-2 CSF levels were increased in CSF during pneumococcal meningitis and whether the concentration was related to severity of disease and outcome, we measured MASP-2 CSF levels in patients and controls. CSF of patients was obtained from the diagnostic lumbar puncture. Control samples were derived from leftover CSF of patients with acute headache in whom a lumbar puncture was performed to exclude a subarachnoid hemorrhage. These control CSF samples all had normal leukocyte count and protein and glucose levels; the final diagnosis in these patients was benign thunderclap headache. CSF was centrifuged and the supernatant was stored at $-80{ }^{\circ} \mathrm{C}$ until assayed. MASP-2, C5a, and C5b-9 levels were determined using commercially available ELISA kits (MyBioSource and Microvue Quidel, respectively) according to manufacturer instructions.

\section{Pneumococcal meningitis mouse model}

To further determine the role of MASP-2 during pneumococcal meningitis and evaluate whether blocking MASP-2 could be used to improve outcome, we used our wellvalidated pneumococcal meningitis mouse model [21]. In this model, $\mathrm{C} 57 \mathrm{BL} / 6 \mathrm{NCrl}$ mice (Charles River Laboratories, Germany), aged 8-12 weeks old, were weighed and 
clinically examined prior to infection. Bacterial meningitis was induced by intracisternal injection of $1 \mu \mathrm{l}$ of $10^{7} \mathrm{CFU} /$ $\mathrm{ml}$ S. pneumoniae serotype 3 (ATCC 6303; American Type Culture Collection, Rockville, MD, USA) under short-term isoflurane anesthesia. Controls were injected with $1 \mu \mathrm{l}$ sterile saline. All animals were clinically examined and scored directly following inoculation and at regular intervals. Clinical scoring consisted of weight loss, activity, time to return to upright position, state of fur, posture, eye discharge or protrusion, respiration rate, irregular/labored breathing, epilepsy, limb paresis, and coordination. In healthy mice, the score was 0 , and mice with a score of 15 or more were critically ill and therefore euthanized. Other humane endpoints were $>25 \%$ weight loss, $\geq 2$ seizures per $15 \mathrm{~min}$, status epilepticus, and hemiparalysis. Mice were euthanized by intraperitoneal injection of ketamine $(190 \mathrm{mg} / \mathrm{kg}$, Eurovet Animal Health, Bladel, the Netherlands) in combination with dexmedetomidine $(0.3 \mathrm{mg} / \mathrm{kg}$, Pfizer Animal Health, Capelle aan den IJssel, the Netherlands). After, euthanasia blood was collected by transcardial puncture and citrated in a 1:4 citrate to blood ratio. CSF was collected by puncture of the cisterna magna and diluted 1:100 in sterile saline. Subsequently, mice were perfused with sterile phosphatebuffered saline and the brain, spleen, and lung were harvested. The right hemisphere was snap frozen in liquid nitrogen, and the left hemisphere, spleen, and lung were taken up in $20 \%$ weight per volume sterile saline and homogenized with a tissue homogenizer. Bacterial titers were determined by plating serial tenfold dilutions of blood, CSF, brain, spleen, and lung homogenates on sheep-blood agar plates and incubating for $16 \mathrm{~h}$ at $37{ }^{\circ} \mathrm{C}$. Citrated blood was centrifuged at $2000 \mathrm{rpm}$ for $15 \mathrm{~min}$ at $4{ }^{\circ} \mathrm{C}$. Tissue homogenates were lysed as described before [21]. Plasma, CSF, and lysed supernatant were stored at $-20{ }^{\circ} \mathrm{C}$ until assayed. Experiments were approved by the Institutional Animal Care and Use Committee of the Academic Medical Center, Amsterdam, the Netherlands.

\section{MASP-2 expression experiments}

To evaluate the expression profile of MASP-2, pneumococcal meningitis was induced and mice were sacrificed at $6 \mathrm{~h}(n=5), 24 \mathrm{~h}(n=5)$, and $48 \mathrm{~h}(n=5)$ after infection. Mice inoculated with sterile saline and sacrificed at $24 \mathrm{~h}$ $(n=5)$ served as control. Mice in the $48 \mathrm{~h}$ group were treated intraperitoneal with ceftriaxone $(100 \mathrm{mg} / \mathrm{kg})$ at $20 \mathrm{~h}$ after infection.

\section{Masp2 deficiency experiments}

To evaluate the effect of Masp2 deficiency on disease severity and mortality, C57BL/6NCrl wild-type (WT) mice $(n=12)$ and Masp2-deficient mice with a C57/BL6N background (Masp $2^{-/-}$, Omeros Corp., $n=12$ ) were infected and observed for $60 \mathrm{~h}$ in a survival experiment.
Mice deficient in Masp2 have been described elsewhere [22]. In a time point experiment, mice were euthanized at 6 (WT infected $n=12$, Masp $^{-/-}$infected $n=12$ ) and 30 (WT infected $n=12$, Masp $^{-/-}$infected $n=12$, WT control $n=6$, Masp $^{-/-} \operatorname{control} n=6$ ) h after infection.

\section{Adjuvant treatment with MASP-2 antibodies}

The previously described recombinant monoclonal antibody AbD04211 inhibits mouse MASP-2 and is able to block lectin pathway activity for 7 days when given intraperitoneally in a single dose of $0.6 \mathrm{mg} / \mathrm{kg}$ [22]. To assess the effect of adjuvant treatment with this antibody against MASP-2 on disease severity and mortality, a survival study was performed. WT mice were infected and treated intraperitoneally at $20 \mathrm{~h}$ after infection with ceftriaxone $(100 \mathrm{mg} / \mathrm{kg})$ in combination with adjuvant treatment and observed for $68 \mathrm{~h}$. Adjuvant treatment consisted of sterile saline $(n=24)$, isotype antibodies (MAB205P, $1 \mathrm{mg} / \mathrm{kg}, n=24)$, or MASP-2 antibodies (AbD04211, $1 \mathrm{mg} / \mathrm{kg}, n=24)$. When the sample size in each group is 24, a 0.05 level two-sided log-rank test for equality of survival curves will have $80 \%$ power to detect a decrease in mortality from 45 and 10\%. In a second experiment, mice were treated with adjuvant sterile saline $(n=18)$ or MASP-2 antibodies (AbD04211, $7 \mathrm{mg} / \mathrm{kg}, n=$ 18 ) and euthanized at 24 and $48 \mathrm{~h}$ after infection.

\section{Protein expression}

IL-1 $\beta$, IL-6, IL-10, keratinocyte chemoattractant (KC), tumor necrosis factor (TNF)- $\alpha$, and macrophage inflammatory protein (MIP)-2 levels were determined in mouse plasma and brain homogenates with Luminex ${ }^{\odot}$ technology (Bio-Rad Laboratories). Expression of MASP-2 and C5b-9 was measured in mouse brain homogenates by ELISA (CUSABIO and USCN Life Science, respectively). Albumin concentrations in brain homogenates were determined with ELISA (ALPCO Diagnostics).

\section{Statistics}

Continuous variables were compared using the MannWhitney $U$ test, and dichotomous variables were compared using the chi-squared test. Survival was analyzed using a log-rank test. Clinical scores were compared using linear mixed models with group/treatment, time, and their interaction as effects. For all models, a random slope was modeled and estimates were corrected for autocorrelation and/or unequal variances where appropriate. For all analyses, a $P$ value $<0.05$ was regarded as significant.

\section{Results}

Cerebrospinal fluid levels of MASP-2 in patients with pneumococcal meningitis

In our nationwide prospective cohort study, 792 episodes of community-acquired pneumococcal meningitis were 
included between March 2006 and May 2012. We investigated MASP-2 levels in cerebrospinal fluid (CSF) samples derived from the diagnostic lumbar puncture, which was available for 307 of 792 pneumococcal meningitis episodes (39\%). Baseline characteristics were similar in patients with and without CSF available (Table 1). We also measured MASP-2 CSF concentrations in 24 controls consisting of patients diagnosed with thunderclap headache in whom lumbar puncture was performed to exclude subarachnoid headache. All controls had normal CSF leukocyte count and glucose and protein levels. We found that pneumococcal meningitis patients had increased levels of MASP-2 in their CSF compared to controls (median 4.77 vs. $1.19 \mathrm{ng} / \mathrm{ml}, P<$ 0.0001). The CSF MASP-2 concentration was significantly higher in patients with an unfavorable outcome, defined as a score of 1 through 4 on the Glasgow Outcome Scale (GOS) [20] compared to patients with a favorable outcome (5.39 vs. $4.36 \mathrm{ng} / \mathrm{ml}, P=0.004$; Fig. 1 ). CSF MASP-2 concentration was higher in deceased

Table 1 Clinical characteristics of 792 pneumococcal meningitis patients with and without CSF available

\begin{tabular}{|c|c|c|c|}
\hline Characteristics & Patients with CSF $(n=307)$ & Patients without CSF $(n=485)$ & $P$ value \\
\hline Age (year) & $62(51-70)$ & $61(51-70)$ & 0.96 \\
\hline Male & $142 / 307(46)$ & 242/458 (53) & 0.32 \\
\hline Duration of symptoms $<24 \mathrm{~h}$ & 140/297 (47) & 233/464 (50) & 0.41 \\
\hline Predisposing conditions & 202/307 (66) & $318 / 485(66)$ & 0.95 \\
\hline Otitis or sinusitis & $121 / 306(40)$ & 205/483 (42) & 0.42 \\
\hline Pneumonia & 28/298 (9) & $53 / 461(11)$ & 0.36 \\
\hline Immunocompromised & 96/307 (31) & $119 / 485(25)$ & 0.04 \\
\hline Symptoms and signs on presentation & a & d & \\
\hline Headache & 221/267 (83) & 345/415 (83) & 0.90 \\
\hline Neck stiffness & $224 / 297(75)$ & $340 / 447(76)$ & 0.84 \\
\hline Systolic blood pressure (mmHg) & $148(130-169)$ & $145(126-165)$ & 0.29 \\
\hline Heart rate (bpm) & $100(86-112)$ & $100(88-115)$ & 0.78 \\
\hline Body temperature $\left({ }^{\circ} \mathrm{C}\right)$ & $39.0(38.2-39.7)$ & $39.0(38.0-39.7)$ & 0.26 \\
\hline Score on Glascow Coma Scale & $10(8-13)^{b}$ & $10(9-13)^{e}$ & 0.70 \\
\hline$<8$ indicating coma & 40/306 (13) & $80 / 483(17)$ & 0.18 \\
\hline Focal neurologic deficits & 90/306 (29) & 139/481 (29) & 0.88 \\
\hline Indexes of CSF inflammation & c & f & \\
\hline Opening pressure & $37(27-43)$ & $35(28-45)$ & 0.66 \\
\hline White blood cell count $\left(/ \mathrm{mm}^{3}\right)$ & $2560(460-6667)$ & $2567(516-7048)$ & 0.60 \\
\hline White blood cell count $<1000 / \mathrm{mm}^{3}$ & 103/295 (35) & 153/465 (33) & 0.57 \\
\hline Protein $(\mathrm{g} / \mathrm{l})$ & $4.1(2.5-6.0)$ & $4.2(2.5-6.2)$ & 0.61 \\
\hline CSF blood glucose ratio & $0.02(0.00-0.23)$ & $0.01(0.00-0.16)$ & 0.06 \\
\hline Positive blood culture & 215/267 (81) & $341 / 423(81)$ & 0.98 \\
\hline \multicolumn{4}{|l|}{ Score on Glasgow Outcome Scale } \\
\hline 1-death & 43/307 (14) & $101 / 485(21)$ & 0.02 \\
\hline 2-vegetative state & 0/307 (0) & $1 / 485(0)$ & 0.43 \\
\hline 3-severe disability & $14 / 307(5)$ & $27 / 485(6)$ & 0.53 \\
\hline 4-moderate disability & $64 / 307(21)$ & $77 / 485(16)$ & 0.08 \\
\hline 5-good recovery & 186/307 (61) & 279/485 (58) & 0.39 \\
\hline
\end{tabular}

Data are number/number evaluated (percentage), and continuous data are mean \pm SD

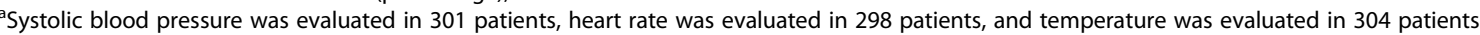

${ }^{\mathrm{b}} \mathrm{S}$ core on Glasgow Coma Scale was evaluated in 306 patients

${ }^{c}$ CSF opening pressure was evaluated in 76 patients, CSF white blood cell count was evaluated in 295 patients, CSF protein was evaluated in 293 patients, and CSF blood glucose ratio was evaluated in 288 patients

${ }^{\mathrm{d}}$ Systolic blood pressure was evaluated in 477 patients, heart rate was evaluated in 472 patients, and temperature was evaluated in 478 patients

${ }^{\text {e}} \mathrm{Score}$ on Glasgow Coma Scale was evaluated in 483 patients

${ }^{\mathrm{f}} \mathrm{CSF}$ opening pressure was evaluated in 89 patients, CSF white blood cell count was evaluated in 464 patients, CSF protein was evaluated in 464 patients, and CSF blood glucose ratio was evaluated in 456 patients 


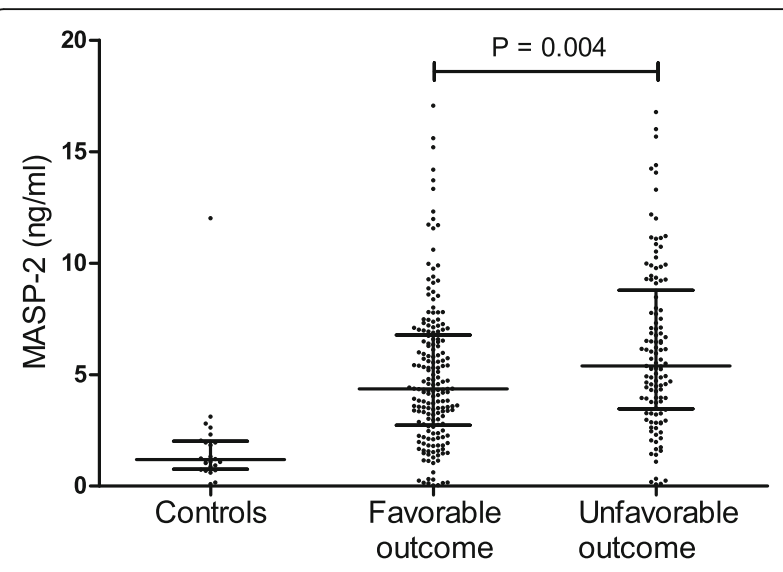

Fig. 1 Cerebrospinal fluid MASP-2 concentration and outcome in patients with pneumococcal meningitis. The MASP-2 concentration was significantly higher in patients with an unfavorable outcome ( $n=121)$ compared to that in patients with a favorable outcome $(n=186)$. Each dot represents an individual patient, lines represent median values, and error bars are interquartile ranges. $P$ value was determined with the Mann-Whitney $U$ test

patients compared to that in survivors, but this did not reach statistical significance $(5.52$ vs. $4.71 \mathrm{ng} / \mathrm{ml}, P=0.090)$. In patients with pneumococcal meningitis, CSF levels of MASP-2 were positively correlated to C5a $(\rho=0.481, P<$ $0.0001)$, C5b-9 $(\rho=0.560, P<0.0001)$ and the CSF protein concentration $(\rho=0.488, P<0.0001)$, but not to CSF leukocyte count $(\rho=0.088, P=0.130)$. Genetic variations in the $M A S P-2$ gene in patients with pneumococcal meningitis did not influence disease severity (Additional file 1).

\section{MASP-2 expression in experimental pneumococcal meningitis}

To study whether MASP-2 was expressed in our pneumococcal meningitis mouse model [21], WT mice were injected into the cisterna magna with $S$. pneumoniae serotype 3 (ATCC $6303 ; n=15$ ) or sterile saline $(n=5)$ and sacrificed at 6,24 , or $48 \mathrm{~h}$ ( $n=5$ per time point). One mouse reached a humane endpoint before the $48 \mathrm{~h}$ time point, and MASP-2 concentrations were determined in brain homogenates of the remaining 19 mice. Mice with pneumococcal meningitis showed increased levels of MASP-2 in brain at 6 (median $2.76 \mu \mathrm{g} / \mathrm{mg}$ tissue, $P=$ 0.008 ) and 24 (median $3.01 \mu \mathrm{g} / \mathrm{mg}$ tissue, $P=0.008$ ) h after infection compared to saline-inoculated mice at $24 \mathrm{~h}$ after inoculation (median $1.43 \mu \mathrm{g} / \mathrm{mg}$ tissue), but no difference was observed after $48 \mathrm{~h}$ (median $1.31 \mu \mathrm{g} / \mathrm{mg}$ tissue).

\section{Masp2 deficiency in experimental pneumococcal meningitis}

To investigate the role of MASP-2 in disease progression in pneumococcal meningitis, we infected Masp $2^{-/-}(n=$ $12)$ and WT $(n=12)$ mice by intracisternal inoculation with S. pneumoniae serotype 3 (ATCC 6303) [21]. At $20 \mathrm{~h}$ after infection, all mice showed signs of illness, and the first animals reached a humane endpoint at $32 \mathrm{~h}$ after infection. All mice reached an endpoint during the 60 -h observation period. Masp $2^{-/-}$mice had a significantly longer survival time compared to WT mice (median survival 44 vs. $36 \mathrm{~h}$, log-rank $P=0.005$; Fig. 2a). Clinical severity scores for Masp2-deficient mice increased slower as compared to those for WT mice $(0.35$ vs. 0.42 points $/ \mathrm{h}, P=0.013)$.

Next, we infected Masp $2^{-/-}(n=24)$ and WT $(n=24)$ mice by intracisternal inoculation with $S$. pneumoniae and euthanized them at 6 and $30 \mathrm{~h}$ after infection. Mice inoculated with sterile saline and euthanized at $30 \mathrm{~h}$ served as control (Masp $2^{-/-} n=6$ and WT $\left.n=6\right)$. One WT mice with pneumococcal meningitis reached an endpoint before the 30-h time point. Bacterial outgrowth in CSF, blood, brain, spleen, and lung was similar between $\mathrm{Masp}^{-/-}$and WT mice at 6 and $30 \mathrm{~h}$ after infection (Additional file 1: Figure S1). Masp $2^{-/-}$mice had significantly lower brain levels of interleukin (IL) $-1 \beta$ (median 3.46 vs. $5.33 \mathrm{ng} / \mathrm{mg}$ tissue, $P=0.045$ ), IL-10 (1.04 vs. $1.70 \mathrm{ng} / \mathrm{mg}$ tissue, $P=0.038)$, and TNF- $\alpha(9.32$ vs. $22.58 \mathrm{ng} / \mathrm{mg}$ tissue, $P=0.025)$ compared to WT mice at $30 \mathrm{~h}$ after infection (Fig. 2b-d). No differences were observed between Masp $2^{-/-}$and WT mice in brain IL-6, $\mathrm{KC}$, and MIP-2 levels or plasma levels of IL-1 $\beta$, IL-6, IL$10, \mathrm{KC}, \mathrm{TNF}-\alpha$, and MIP-2. Complement activation, as indicated by brain levels of C5b-9, was also similar between $M a s p 2^{-/-}$and WT mice $30 \mathrm{~h}$ post-infection $(P=$ 0.88; Fig. 2e). During bacterial meningitis, destruction of the blood-brain barrier is related to disease progression and is reflected by increased brain albumin levels [11]. Brain albumin content was elevated in Masp $2^{-/-}$(312.23 vs. $86.27 \mu \mathrm{g} / \mathrm{mg}$ tissue, $P=0.006)$ and WT (262.21 vs. $42.85 \mu \mathrm{g} / \mathrm{mg}$ tissue, $P<0.001)$ mice at $30 \mathrm{~h}$ after infection compared to saline-inoculated mice. No differences were observed between Masp $2^{-/-}$and WT mice at $6(P=0.80)$ and $30(P=0.74)$ h post-infection.

\section{Adjuvant treatment with MASP-2 antibodies}

We compared the effect of inhibitory MASP-2 antibodies with saline in our treatment model. Thirty-six WT mice were infected intracisternally with $S$. pneumoniae serotype 3 (ATCC 6303). At $20 \mathrm{~h}$ post-infection, all mice were treated with ceftriaxone intraperitoneally plus either MASP-2 antibodies $(n=18)$ or saline $(n=18)$ and euthanized at 24 and 48 h. MASP-2 antibodytreated mice had reduced brain levels of C5b-9 compared to saline-treated mice at $24 \mathrm{~h}$ (median $1.08 \mathrm{vs}$. $2.53 \mu \mathrm{g} / \mathrm{mg}$ tissue, $P=0.017)$ and $48 \mathrm{~h}(0.85 \mathrm{vs} .1 .25 \mu \mathrm{g} /$ mg tissue, $P=0.052$ ) after infection. Plasma C5b-9 levels were reduced in MASP-2 antibody-treated mice compared to saline-treated mice at $24 \mathrm{~h}$ after infection $(0.42$ vs. $0.63 \mu \mathrm{g} / \mathrm{ml}, P=0.022)$. MASP-2 antibody treatment was associated with lower plasma levels of TNF- $\alpha$ 

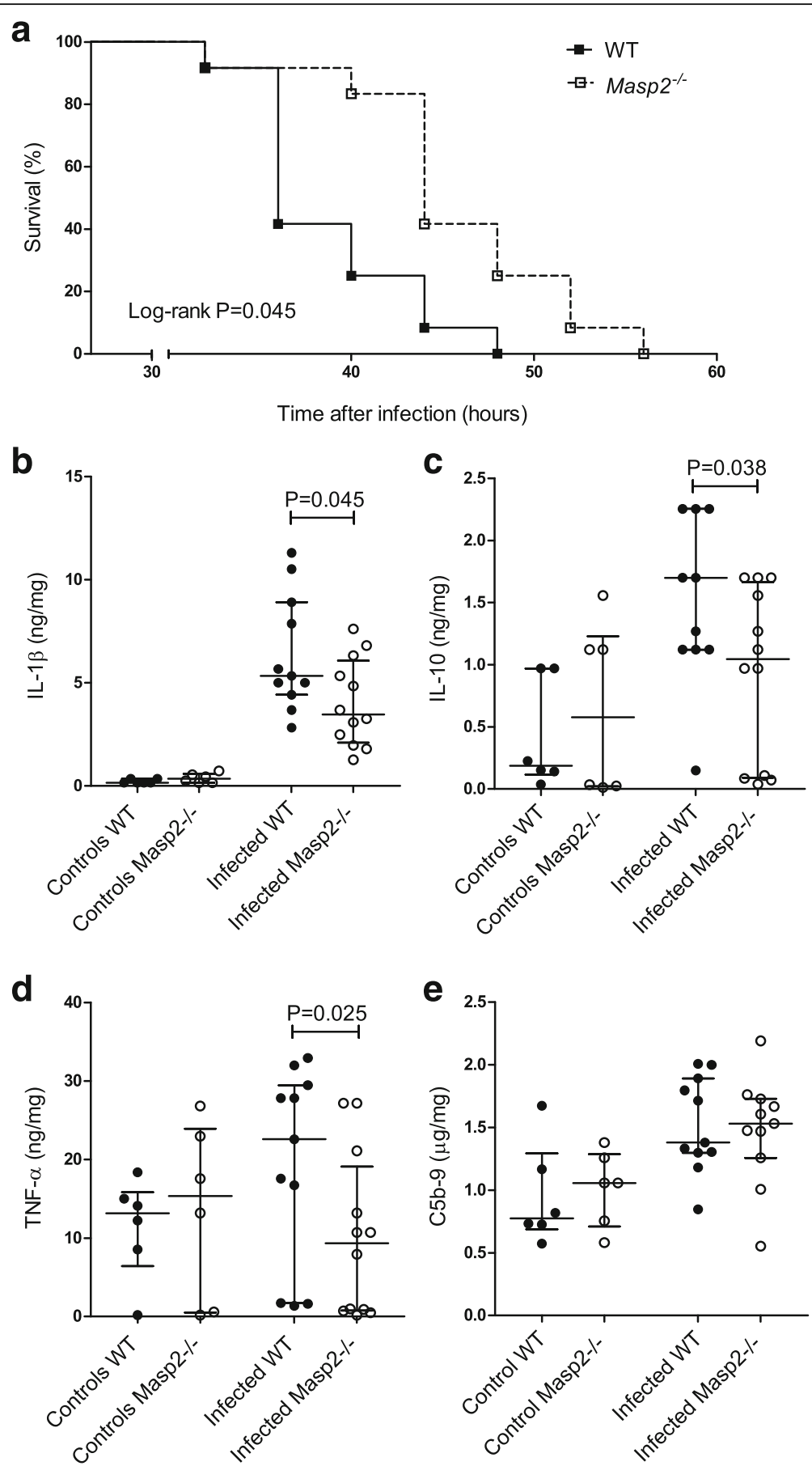

Fig. 2 Functional role of MASP-2 in pneumococcal meningitis mouse model. Kaplan-Meier curve showing increased survival in Masp2 $2^{-/-}$mice during pneumococcal meningitis (a). Cytokines and complement levels were measured in brain. Masp2 ${ }^{-/-}$mice had significantly lower brain

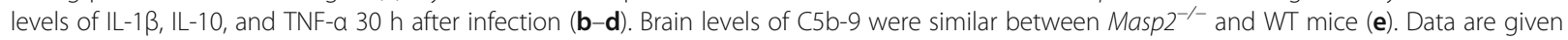
as medians and 75 th quartile; $P$ values were determined with the Mann-Whitney $U$ test

compared to saline at $48 \mathrm{~h}$ after infection (median 0.10 vs. $0.25 \mathrm{ng} / \mathrm{ml}, P=0.044)$. No differences were observed in bacterial CFUs (Additional file 1: Figure S2), brain levels of IL-1 $\beta$, IL-6, IL-10, KC, TNF- $\alpha$, and MIP-2, and plasma levels of IL-1 $\beta$, IL-6, IL-10, KC, and MIP-2 between MASP-2 antibody- and saline-treated mice.

Next, we evaluated the effect of adjuvant treatment with the MASP-2 antibodies on clinical severity and survival. 
Pneumococcal meningitis was induced in 72 WT mice; three mice showed a limb paresis directly following inoculation, and two mice reached a humane endpoint before treatment was given and were excluded from the experiment. The remaining 67 mice all showed signs of infection $20 \mathrm{~h}$ post-infection and were randomized for antibiotic therapy consisting of ceftriaxone intraperitoneally in combination with either saline $(n=22)$, isotype antibodies $(n=23)$, or MASP-2 antibodies $(n=22)$. The 68 -h mortality rates were 8 of 22 (36\%) in the saline group, 7 of 23 (30\%) in the isotype antibody group, and 3 of 22 (14\%) in the MASP-2 antibody group (Fig. 3a; Fisher's exact test for overall difference $P=0.21$ ). Mortality in the MASP-2 antibody-treated group was lower compared to sham treatment, but this did not reach statistical significance (MASP-2 Ab vs. saline $P=0.088$; MASP-2 Ab vs. isotype antibody $P=0.210$ ). Clinical severity scores for MASP-2 antibody-treated mice increased significantly slower as compared to saline (Fig. 3b; 0.017 vs. 0.103 points $/$ h, $P=$ $0.002)$ and isotype antibody-treated mice ( 0.0017 vs. 0.080 points/h, $P=0.019$ ).

\section{Discussion}

Our results show that MASP-2 contributes to severity and outcome in pneumococcal meningitis. In patients with pneumococcal meningitis, MASP-2 concentration was elevated in the CSF and high levels were associated with poor functional outcome. In experimental pneumococcal meningitis, Masp2 deficiency led to decreased disease severity through decreased brain inflammation. Adjuvant treatment with MASP-2-specific monoclonal antibodies led to a decreased level of complement activation and disease severity.

The identified role of MASP-2 is consistent with the two-edged sword theory on complement activation in infectious disease [23]. A less readily activated complement system leads to increased susceptibility to infection but reduced severity of inflammation, which is the key pathogenic mechanism in pneumococcal meningitis. A more readily activated complement system reduces the risk of infection, but results in a poor prognosis in bacterial meningitis [13, 24]. Masp2 deficiency was previously shown to increase the risk of infection but we
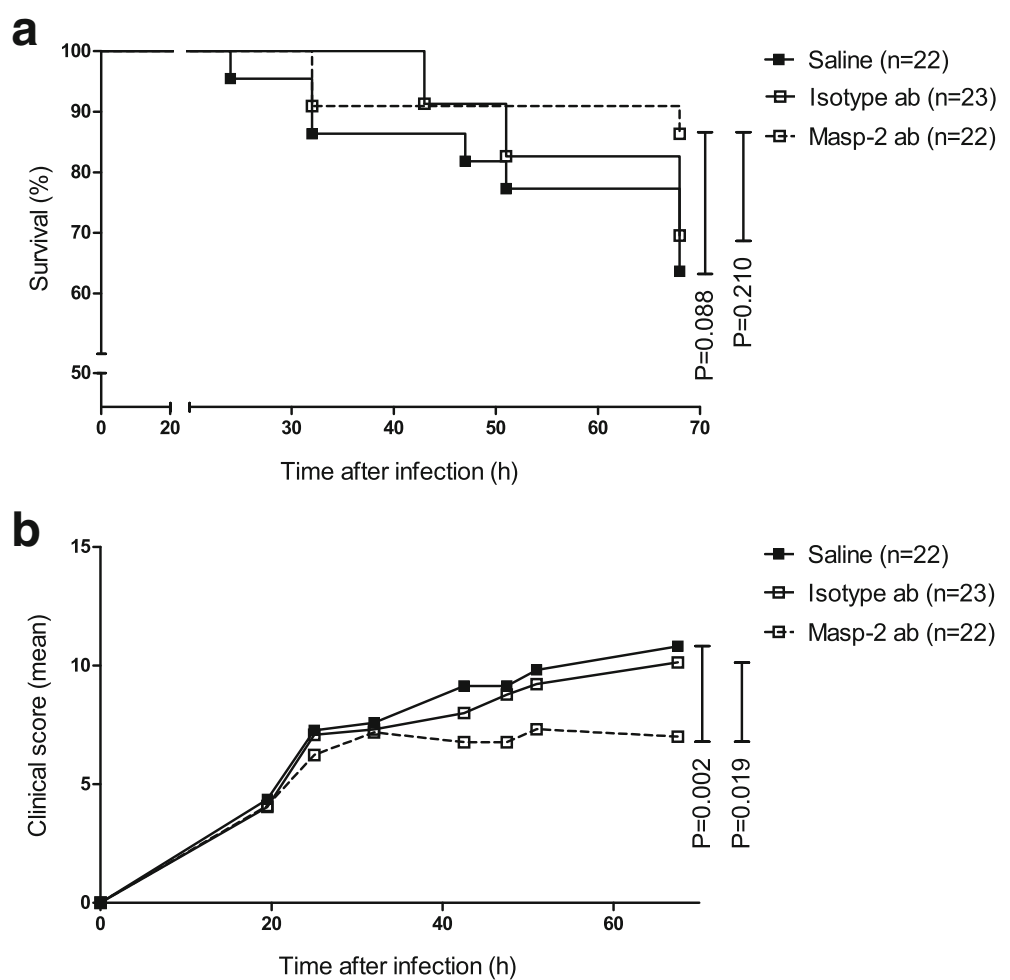

Fig. 3 The effect of adjuvant treatment with the MASP-2 antibodies on clinical severity and survival in experimental pneumococcal meningitis. Kaplan-Meier curve of WT mice with pneumococcal meningitis treated intraperitoneally $20 \mathrm{~h}$ after infection with ceftriaxone $(100 \mathrm{mg} / \mathrm{kg})$ in combination with adjuvant treatment and observed for $68 \mathrm{~h}$ (a). Adjuvant treatment consisted of sterile saline, isotype antibodies (MAB205P, $1 \mathrm{mg} / \mathrm{kg}$ ), or MASP-2 antibodies (D04211, $1 \mathrm{mg} / \mathrm{kg}$ ). There was no difference in survival between groups. $P$ values were determined with the log-rank test. Clinical severity scores for MASP-2 antibody-treated mice increased slower as compared to saline- $(0.017 \mathrm{vs}$. 0.103 points/h) and isotype antibody (0.0017 vs. 0.080 points/h)-treated mice (b). $P$ values were determined using linear mixed models with group/treatment, time, and their interaction as effects 
now show this leads to a reduced inflammatory response during meningitis, thereby improving survival.

Previous studies in pneumococcal infection showed increased disease severity among Masp2-deficient and MASP-2 antibody-treated mice, which was mainly driven by decreased opsonization of bacteria, leading to increased bacterial counts in the peripheral blood [18]. In our study, neither Masp2 deficiency nor MASP-2 antibody treatment influenced bacterial counts in the blood or brain, and the effect on disease severity seemed to be driven by a decreased inflammatory response. In pneumococcal meningitis, complement activation, notably in the final common pathway, has previously been found to cause brain damage and was associated with an adverse outcome [11, 25]. Reduction of complement activation in C3-deficient mice resulted in less intracranial complications in pneumococcal meningitis, but the lack of C3-mediated opsonophagocytosis led to decreased bacterial clearance and worsened outcome [26]. We hypothesize that in case of Masp2 deficiency, $\mathrm{C} 3 \mathrm{~b}$, formed via the classical or alternative pathway, is still able to opsonize the bacteria for phagocytosis. This is supported by similar levels of C5b-9 in brains of Masp2-deficient and WT mice as an indicator of total complement activation. MASP-2 antibody-treated mice had reduced brain levels of C5b-9 compared to salinetreated infected mice. In our treatment model, the MASP2 antibody was given in conjunction with antibiotic therapy, while previous studies were performed without antibiotic therapy [18]. Another explanation for the difference in results between these previous studies and our study is the difference in pneumococcal serotypes (serotype 2 vs. 3). The binding of M-ficolin, in association with MASP-2, of $S$. pneumoniae has been shown to be serotype-specific, at least for certain pneumococcal serotypes [27]. Other work showed that binding of S. pneumoniae by lectin pathway pattern recognition molecules occurs only with a minority of serotypes and that L-ficolin specifically binds to capsule constituents [28]. Although we found no difference in C5b-9 brain levels between Masp2-deficient and WT mice after infection, Masp 2 deficiency was associated with decreased brain cytokine levels and an increased survival. We hypothesize that the difference may be explained by a different pace of complement activation in Masp2-deficient mice compared to wildtype mice. Masp2-deficient mice could reach a full activation state of the complement system at a later time point, which would explain the decreased inflammatory response and increased survival.

Adjunctive treatment with MASP-2 antibodies resulted in a reduction of disease severity and tended to reduce mortality despite having no effect on either bacterial outgrowth in the CSF and blood or antibioticinduced bacterial killing in experimental pneumococcal meningitis. In our treatment model, we observed no effect on brain cytokine levels, but there was an effect on total C5b-9 brain levels. The protective effect holds promise for future treatment of patients with pneumococcal meningitis, but the effect size seemed to be smaller than previously observed for adjunctive treatment with anti-C5 antibodies [13, 16]. However, experiments using adjunctive treatment with anti-C5 antibodies were performed in a model of pneumococcal meningitis with high disease severity, with a mortality rate of $100 \%$ in the placebo group [16]. C1 inhibitors have been shown to reduce clinical severity, increase bacterial clearance, and decrease CSF and meningeal inflammation in a rat model of pneumococcal meningitis [29]. Altogether, these studies suggest that inhibition of complement activation may be beneficial in pneumococcal meningitis.

Genetic variations in the Masp2 gene did not explain inter-individual differences in disease course. However, this does not negate the importance of MASP-2 in activation of complement in pneumococcal meningitis. Involvement of the lectin pathway in invasive pneumococcal disease has been shown by genetic association studies on mannose-binding lectin (MBL)2 deficiency [7]. In a prospective genetic association study, including 299 patients with pneumococcal meningitis and 216 controls, we previously showed that the risk for contracting pneumococcal meningitis was substantially increased for white individuals homozygous with the defective MBL2 0/ 0 genotype (odds ratio 8.21 , 95\% confidence interval $1.05-$ 64.1; $P=0.017$ ) [30]. CSF MBL levels were significantly lower in patients with the $\mathrm{A} / 0$ and $0 / 0$ genotype compared to homozygotes with the wild-type alleles (A/A; $P<0.001)$. CSF MBL levels were positively correlated with $\mathrm{C} 3 \mathrm{a}$ and $\mathrm{iC} 3 \mathrm{~b}$ levels, indicating complement activation by the lectin pathway.

Our study has several limitations. First, selection bias could have been introduced since CSF was only available in a portion of patients included in the cohort. However, patients with and without CSF available had similar baseline and clinical characteristics, and therefore, selection bias is unlikely. Second, our analysis of CSF MASP2 levels and disease severity is associative and cannot be seen as proof of causation. Third, we did not backcross the mice knockout and wild-type strains because of time and cost considerations. Although the animals are from the same genetic background (C57/BL6N), they were not identical except for the Masp2 gene. This means we cannot rule out that an unidentified small variation between strains may contribute to the identified phenotype. However, this does not influence the CSF and antibody treatment studies, suggesting a similar role of MASP2 as established in the knockout experiments. Fourth, our animal experiments were not performed in a blinded and randomized manner, which may lead to an overestimation of the treatment effect. Although 
parameters of inflammation and outcome seem to be consistent, this is not according to current standards [31]. Then, randomized controlled experimental trials are needed comparing adjunctive treatment with MASP-2 antibodies, with and without adjunctive dexamethasone therapy. Such experimental trials should be adequately powered to detect differences in mortality, done with meningitis caused by different serotypes, and ideally be performed in different experimental laboratories.

\section{Conclusions}

Our study stresses the important role of MASP-2 in pneumococcal meningitis and suggests that MASP-2 inhibitory antibodies can attenuate the harmful inflammatory response during pneumococcal meningitis. Eventually, anti-MASP-2 antibodies may be used for complement inhibition in patients as currently these are studies used in clinical trials (ClinicalTrials.gov Identifier NCT02222545). Although further experimental proof is needed to confirm our results, our results present a promising target for future treatment of pneumococcal meningitis.

\section{Additional file}

Additional file 1: Supplemental Tables 1 and 2, and Figures 1 and 2 (DOC 202 kb)

\section{Abbreviations}

C5: Complement component 5; CSF: Cerebrospinal fluid; IL: Interleukin; KC: Keratinocyte chemoattractant; MASP-2: Mannose-binding lectinassociated serine protease; MBL: Mannose-binding lectin; MIP: Macrophage inflammatory protein; TNF: Tumor necrosis factor

\section{Acknowledgements}

This work was supported by grants from the European Research Council (ERC Starting Grant [proposal/contract 281156]), Netherlands Organization for Health Research and Development (ZonMw; NWO-Vidi grant 2010 [proposal/ contract 016.116.358]), and Omeros (all to DvdB).

\section{Availability of data and materials}

Data of the MeninGene study is available for all researchers at www.MeninGene.eu

\section{Authors' contributions}

ESK included the patients in the cohort, performed the experiments, and drafted the manuscript. MVS designed and performed the experiments. BF carried out the molecular genetic analysis. MWT and AHZ provided the statistical support. FB designed the molecular genetic analysis. AvdE designed the study. MCB conceived the study and participated in its design and coordination. DvdB conceived the study, participated in its design and coordination, and drafted the manuscript. All authors read and approved the final manuscript.

\section{Competing interests}

The authors declare that they have no competing interests.

\section{Consent for publication}

Not applicable; our manuscript does not contain any individual persons data.

\section{Ethics approval}

The study was approved by the medical ethical committee of the Academic Medical Centre, Amsterdam, the Netherlands.
Experiments were approved by the Institutional Animal Care and Use Committee of the Academic Medical Center, Amsterdam, the Netherlands.

\section{Author details}

${ }^{1}$ Department of Neurology, Academic Medical Center, Amsterdam Neuroscience, Amsterdam, The Netherlands. ${ }^{2}$ Department of Clinical Epidemiology, Biostatistics, and Bioinformatics, Academic Medical Center, University of Amsterdam, Amsterdam, The Netherlands. ${ }^{3}$ Department of Genome Analysis, Academic Medical Center, Amsterdam, The Netherlands. ${ }^{4}$ Department of Medical Microbiology, Center of Infection and Immunity Amsterdam (CINIMA), Academic Medical Center, Amsterdam, The Netherlands. ${ }^{5}$ The Netherlands Reference Laboratory for Bacterial Meningitis, Center of Infection and Immunity Amsterdam (CINIMA), Academic Medical Center, Amsterdam, The Netherlands. ${ }^{6}$ Department of Neurology, Academic Medical Center, University of Amsterdam, Amsterdam Neuroscience, PO Box 226601100 DD Amsterdam, The Netherlands.

Received: 10 September 2016 Accepted: 30 November 2016 Published online: 03 January 2017

\section{References}

1. Lozano R, Naghavi M, Foreman K, Lim S, Shibuya K, Aboyans V, Abraham J, Adair T, Aggarwal R, Ahn SY, et al. Global and regional mortality from 235 causes of death for 20 age groups in 1990 and 2010: a systematic analysis for the Global Burden of Disease Study 2010. Lancet. 2012;380(9859):2095-128.

2. Bijlsma MW, Brouwer MC, Kasanmoentalib ES, Kloek AT, Lucas MJ, Tanck MW, van der Ende A, van de Beek D. Community-acquired bacterial meningitis in adults in the Netherlands, 2006-14: a prospective cohort study. Lancet Infect Dis. 2016;16(3):339-47.

3. Brouwer MC, Tunkel AR, van de Beek D. Epidemiology, diagnosis, and antimicrobial treatment of acute bacterial meningitis. Clin Microbiol Rev. 2010;23(3):467-92.

4. van de Beek D, de Gans J, Spanjaard L, Weisfelt M, Reitsma JB, Vermeulen M. Clinical features and prognostic factors in adults with bacterial meningitis. N Engl J Med. 2004:351(18):1849-59.

5. van de Beek D, de Gans J, Tunkel AR, Wijdicks EF. Community-acquired bacterial meningitis in adults. N Engl J Med. 2006:354(1):44-53.

6. Hoogman M, van de Beek D, Weisfelt M, de Gans J, Schmand B. Cognitive outcome in adults after bacterial meningitis. J Neurol Neurosurg Psychiatry. 2007;78(10):1092-6.

7. Brouwer MC, de Gans J, Heckenberg SG, Zwinderman AH, van der Poll T, van de Beek D. Host genetic susceptibility to pneumococcal and meningococcal disease: a systematic review and meta-analysis. Lancet Infect Dis. 2009:9(1):31-44.

8. Kasanmoentalib ES, Brouwer MC, van de Beek D. Update on bacterial meningitis: epidemiology, trials and genetic association studies. Curr Opin Neurol. 2013;26(3):282-8

9. Ferwerda $B$, Valls Seron $M$, Jongejan $A$, Zwinderman $A H$, Geldhoff $M$, van der Ende A, Baas F, Brouwer MC, van de Beek D. Variation of 46 innate immune genes evaluated for their contribution in pneumococcal meningitis susceptibility and outcome. EBioMedicine. 2016;10:77-84

10. Davila S, Wright VJ, Khor CC, Sim KS, Binder A, Breunis WB, Inwald D, Nadel

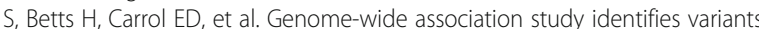
in the $\mathrm{CFH}$ region associated with host susceptibility to meningococcal disease. Nat Genet. 2010:42(9):772-6.

11. Mook-Kanamori BB, Geldhoff M, van der Poll T, van de Beek D. Pathogenesis and pathophysiology of pneumococcal meningitis. Clin Microbiol Rev. 2011; 24(3):557-91.

12. Valls Seron $M$, Ferwerda $B$, Engelen-Lee J, Geldhoff $M$, Jaspers $V$ Zwinderman AH, Tanck MW, Baas F, van der Ende A, Brouwer MC, et al. Vakt murine thymoma viral oncogene homolog 3 (AKT3) contributes to poor disease outcome in humans and mice with pneumococcal meningitis. Acta Neuropathol Commun. 2016:4(1):50

13. Woehrl B, Brouwer MC, Murr C, Heckenberg SG, Baas F, Pfister HW, Zwinderman AH, Morgan BP, Barnum SR, van der Ende A, et al. Complement component 5 contributes to poor disease outcome in humans and mice with pneumococcal meningitis. J Clin Invest. 2011; 121(10):3943-53.

14. Savva A, Brouwer MC, Roger T, Valls Seron M, Le Roy D, Ferwerda B, van der Ende A, Bochud PY, van de Beek D, Calandra T. Functional polymorphisms of macrophage migration inhibitory factor as predictors of morbidity and 
mortality of pneumococcal meningitis. Proc Natl Acad Sci U S A. 2016; 113(13):3597-602.

15. Brouwer MC, Meijers JC, Baas F, van der Ende A, Pfister HW, Giese A, van de Beek D, Koedel U. Plasminogen activator inhibitor-1 influences cerebrovascular complications and death in pneumococcal meningitis. Acta Neuropathol. 2014;127(4):553-64.

16. Kasanmoentalib ES, Valls Seron M, Morgan BP, Brouwer MC, van de Beek D. Adjuvant treatment with dexamethasone plus anti-C5 antibodies improves outcome of experimental pneumococcal meningitis: a randomized controlled trial. J Neuroinflammation. 2015;12:149.

17. Brown JS, Hussell T, Gilliland SM, Holden DW, Paton JC, Ehrenstein MR Walport MJ, Botto M. The classical pathway is the dominant complement pathway required for innate immunity to Streptococcus pneumoniae infection in mice. Proc Natl Acad Sci U S A. 2002;99(26):16969-74.

18. Ali YM, Lynch NJ, Haleem KS, Fujita T, Endo Y, Hansen S, Holmskov U, Takahashi K, Stahl GL, Dudler T, et al. The lectin pathway of complement activation is a critical component of the innate immune response to pneumococcal infection. PLoS Pathog. 2012;8(7):e1002793.

19. Brouwer MC, Heckenberg SG, de Gans J, Spanjaard L, Reitsma JB, van de Beek D. Nationwide implementation of adjunctive dexamethasone therapy for pneumococcal meningitis. Neurology. 2010;75(17):1533-9.

20. Jennett B, Teasdale G, Braakman R, Minderhoud J, Knill-Jones R. Predicting outcome in individual patients after severe head injury. Lancet. 1976; 1(7968):1031-4

21. Mook-Kanamori B, Geldhoff M, Troost D, van der Poll T, van de Beek D. Characterization of a pneumococcal meningitis mouse model. BMC Infect Dis. 2012;12:71.

22. Schwaeble WJ, Lynch NJ, Clark JE, Marber M, Samani NJ, Ali YM, Dudler T, Parent B, Lhotta K, Wallis $\mathrm{R}$, et al. Targeting of mannan-binding lectinassociated serine protease-2 confers protection from myocardial and gastrointestinal ischemia/reperfusion injury. Proc Natl Acad Sci U S A. 2011; 108(18):7523-8.

23. Adriani KS, Brouwer MC, Geldhoff M, Baas F, Zwinderman AH, Paul Morgan B, Harris CL, van der Ende A, van de Beek D. Common polymorphisms in the complement system and susceptiblity to bacterial meningitis. J Infect. 2013;66(3):255-62.

24. Mook-Kanamori BB, Brouwer MC, Geldhoff M, Ende A, van de Beek D. Cerebrospinal fluid complement activation in patients with pneumococcal and meningococcal meningitis. J Infect. 2014;68(6):542-7.

25. Tauber MG, Khayam-Bashi H, Sande MA. Effects of ampicillin and corticosteroids on brain water content, cerebrospinal fluid pressure, and cerebrospinal fluid lactate levels in experimental pneumococcal meningitis. J Infect Dis. 1985;151(3):528-34.

26. Rupprecht TA, Angele B, Klein M, Heesemann J, Pfister HW, Botto M, Koedel $\mathrm{U}$. Complement $\mathrm{Clq}$ and $\mathrm{C} 3$ are critical for the innate immune response to Streptococcus pneumoniae in the central nervous system. J Immunol. 2007; 178(3):1861-9.

27. Kjaer TR, Hansen AG, Sorensen UB, Holm AT, Sorensen GL, Jensenius JC, Thiel S. M-ficolin binds selectively to the capsular polysaccharides of Streptococcus pneumoniae serotypes $19 \mathrm{~B}$ and $19 \mathrm{C}$ and of a Streptococcus mitis strain. Infect Immun. 2013;81(2):452-9.

28. Krarup A, Sorensen UB, Matsushita M, Jensenius JC, Thiel S. Effect of capsulation of opportunistic pathogenic bacteria on binding of the pattern recognition molecules mannan-binding lectin, L-ficolin, and H-ficolin. Infect Immun. 2005;73(2):1052-60.

29. Zwijnenburg PJ, van der Poll T, Florquin S, Polfliet MM, van den Berg TK, Dijkstra CD, Roord JJ, Hack CE, van Furth AM. C1 inhibitor treatment improves host defense in pneumococcal meningitis in rats and mice. J Infect Dis. 2007;196(1):115-23.

30. Brouwer MC, Baas F, van der Ende A, van de Beek D. Genetic variation and cerebrospinal fluid levels of mannose binding lectin in pneumococcal meningitis patients. PLoS One. 2013;8(5):e65151.

31. Landis SC, Amara SG, Asadullah K, Austin CP, Blumenstein R, Bradley EW, Crystal RG, Darnell RB, Ferrante RJ, Fillit H, et al. A call for transparent reporting to optimize the predictive value of preclinical research. Nature. 2012;490(7419):187-91.

\section{Submit your next manuscript to BioMed Central and we will help you at every step:}

- We accept pre-submission inquiries

- Our selector tool helps you to find the most relevant journal

- We provide round the clock customer support

- Convenient online submission

- Thorough peer review

- Inclusion in PubMed and all major indexing services

- Maximum visibility for your research

Submit your manuscript at www.biomedcentral.com/submit
Biomed Central 